\title{
Batha Gelenai: A Traditional Game of Bodos of the Baksa District of Assam
}

\author{
Rita Daimary ${ }^{1^{*}}$ and Bhupen Narzaree ${ }^{2}$ \\ ${ }^{1}$ Research Scholar, ${ }^{2}$ Professor, Department of Bodo, Gauhati University, Assam, India \\ Received 09 March 2019, Accepted 11 May 2019, Available online 13 May 2019, Vol.7 (May/June 2019 issue)
}

\begin{abstract}
All the traditional games and sports of Bodos are played by its own tradition. Batha Gelenai is one of the most important Traditional Games and Recreation of the Bodos of Assam. Traditionally two kinds of Batha Games are played by the Bodos of Assam. One of them is "Khunthiya Batha" and another one is "Dwikhor Batha". Both of them are played by different methods. But in this paper only Khunthiya Batha will be discussed. It is played for enjoyment only. Normally this Game is a kind of Group Game, played by young boy's only. But sometime adult male also played this Game for their enjoyment. Dry and open paddy field is the best playground for this Game and still today it is played at dry season. It is also a kind of very interesting and dangerous Game of the Bodos. Lack of practice sometimes some players are to be injured during this Game. Now a day's use of some playing materials like use of Begors during the play has changed. Today Marbles are also used in place of Begors. By observing whole the process and methods of Batha Gelenai it can be said that it is like a present Cricket Game. So it is needed for a deep study and updated for the modernization of this Game.
\end{abstract}

Keywords: Traditional, Games and Sports, Bodos, Assam, Batha-Gelenai, Khunthiya, Batha, Laothi, Begor.

\section{Introduction}

Games and sports form an important part of a social life. It gives us encouragement to face all the hard challenges of life. It provides us physical strength which is always needed for doing our work. Without games people becomes dull, boring, pessimist and failure in life. It is also a significant value in student's life.

\section{According to Robert A. Georges;}

"Play is a form of expressive behaviour common among all human beings and manifested overtly in all cultures"1. Again remarks S.N. Sarma, "sports and pastime are integral parts of a vibrant social life. A nation or a community devoid of these life-sustaining activities is physically and mentally retarded and is devoid of gusto for life" ${ }^{\prime 2}$.

From the very beginning the Bodos have some games and recreations with their own methods. "They played them to forget their tired and to busy for next works, and to enjoy in their busy life". Today these games and sports are updated and recognised as a rural games and sports of National as well as International level. Batha Gelenai is

*Corresponding author's ORCID ID: 0000-0002-2919-035X DOI: https://doi.org/10.14741/ijmcr/v.7.3.7 one of the most important Traditional games of the Bodos. Detail of this game will be discussed in this paper.

\section{Area of the Research}

The area of this the Research is traditional Games and Recreations of the Bodos with special reference to the Baksa District.

\section{Aims and objectives of the Research}

Culture is another most effective media of the Bodo community to express and expose their strong century old social and cultural heritage before the world community. Literary, in today's context, Bodo is a well developed language. But unlike many of the Tribal society of India, the Bodo culture is yet to be developed on pure scientific platform with a true scientific spirit. It is true that in the advent of today's Information and Technology if any culture of the world is not based on scientific analysis it cannot enjoy the full benefit of Information and technology in practice.

So, it is the aim of propose research work to collect the traditional games and recreations of the Bodos, to preserve and developed on pure scientific platform with a true scientific spirit. 


\section{Methodology of Research}

The Descriptive and Analytical method has been used for this research. This research will completely depend on Field work. For the collection of Primary datas some questionnaires will be distributed to the different age groups. Again interviewed and collect them from different Informants by different age groups of the several places. For the collection of datas camera, tape recorder etc. are used.

The datas of the secondary sources will be collect from the reference books, magazine and journals. After collecting the datas the paper is prepared by observation method.

\section{Batha Gelenai}

Batha Gelenai is one of the most important Traditional games of the Bodos. Traditionally two kinds of Batha Games are played by the Bodos of Baksa District. One of them is "Khunthiya Batha" and another one is "Dwikhor Batha". Both of them are played by different methods. But in this paper only Khunthiya Batha will be discussed.

\section{Khunthiya Batha}

Khunthiya Batha is one of the most important parts of Batha Gelenai. It is also one of the most important part of Traditional Games and recreations of the Bodos. Traditionally this game is played by the Bodos of Baksa District from the very beginning. It is a kind of Group Game specially played by the Boys of the Bodos in dry season on an open field or a specific playground or a paddy field. But traditionally paddy filed is the most preferable place for this game.

\section{Process of Playing the Game}

There are so many processes regarding the playing of this game. Such as- group selection, playground selection, playing materials and score of the play etc.

\section{Group Selection}

Traditionally this game is played between two groups. There is no limit of the players in a group. The number of players in a group are depends on the (size of the field) length and broad of the playground. Traditionally Six (6) to Ten (10) numbers of players are plays in a group.

Before playing the game, group selection is one of the most important parts of this game. The whole process of group selection for this game is very interesting. No players have the right to joined in any group by their will. Traditionally there is a specific process of group selection.

There are two heads of two groups which is called Bwrai and Burwi. They are the head (Like a captain) of both the groups.
Firstly, observing whole the players two strongest players are selected as Bwrai and Burwi and they are recognised as a captains of both the groups. Secondly, other remaining players are paired by the Bwrai and Burwi according to their physical fitness (Height, Age and Strong). They are requested to go away to a secret place to take any two another names or bringing any two leafs by their own discussion and placed before Bwrai and Burwi. Bwrai and Burwi have the right to beg any one name or select any one leaf placed before them for the selection of their team member. If one pair is begged or selected by Bwrai then another pair will be begged or select by Burwi alternatively. Both the groups are selected and completed by this process.

\section{Playground Selection}

Playground selection is also one of the most important parts of playing this game. There is no specific area (size) or place of the field to play this game. It may be school playground or any open field or a paddy field. But open field or paddy field is the most preferable place for this game. As earlier mentioned that the number of players in a group are depends on the (size of the field) length and broad of the playground. On the other hand the area (size) of the field is also depends on the numbers of the players. The area (size) and place of the playground is selected by the reorganization of both the team.

\section{Playing Materials}

There are five kinds of playing materials are used for this game. These materials are- Khunthiya, Batha, Laothi (batha bugra), Laothi (batha bufinna horgra) and Begors (for counting the scores).

\section{Khunthiya}

Khunthiya is one of the most important playing materials of the Batha Game. The Khunthiya of the play must be 3 to 3.5 feet length small but tight (full matured) bamboo or small but tight (full matured) tree or any branch of a tree (4 to 4.5 ) inch in diameter.

\section{Batha}

Batha is second most important playing materials for this Game. The very interesting point of the length of the Batha selection is that the Batha must be Homzwbgase or Muthase (2.5 to 3 inches). It may be tight (full matured) bamboo or tree or branch of tree ( 3 to 3.5 inches) in diameter.

\section{Laothi (batha bugra)}

It is third most important playing materials for this play. The length of the Laothi (batha bugra) must be almost 1 foot of small but tight (full matured) bamboo or tree or branch of any tree ( 3 to 3.5 inches) in diameter. 


\section{Laothi (batha bufinna horgra)}

Fourth important but not so must important playing materials for Batha gelenai is Laothi (batha bufinna horgra); which is same as Laothi (batha bugra).

\section{Begors (For counting the scores)}

Fifth and last most important playing materials for this game is Begors (for counting the scores). It is used for counting the scores made by the players. The begors may be Narkha phithai or Nimista phithai or any other small phithai or begors which can be keep more in a place. With play two holes are made by players to keep the begors for counting score properly. One hole is used as stockiest and another one is counting hole. When the player scored 1 point (count "Er to Paas") then 1 number of begor keeps in the counting hole.

Before playing the game a toss system is also a most important part of this game. The toss system of this game is also very interesting. Traditionally there are several kinds of toss systems for this game. One outsider person keeps any object in a hand but both the hands are closed and asked the captains to identify the object in which hand. Who can identify the object in which hand will be winning the toss. They have the right to beat first and another team will be the opponent group.

The Khunthiya is put tightly on the middle of the playground keeping 2.5 to 3 feet upward the ground and keep the Batha on the Khunthiya and heat it upward as fast as possible with Laothi (batha bugra) by first beater. The fielders surrounding by him are tried to catches the Batha on upward. And sometimes they tried to sort it by their Laothi( Batha bufinna horgra) to nearest of the Khunthiya for their opportunity to through the Batha. (If the Bathe is catches by fielder in upward without touching the ground then the beater will be declared as dead or out. But if the fielder cannot catch the Batha in upward then he threw the Bath and tried to touch the Khunthiya. On the other hand the Batha bugra (beater) also tried to heat again the Batha in a long distance by a sound "Abwi". And he starts his counting by a song " $E r$, Ver, Rwo, Raas, Paas". From "Er to Paas" a complete one counting and gets one score. It is counted again and again up to Khunthiya.

But there is also a different form of beating Batha from the beginning to counting "Paas". Every beginner can beat their Batha through Khunthiya only and he has no right to beat the Batha on Khunthiya for second time up to his dead or out. Other all the beatings are different with their counting.

If the count is ended with " $E r$ " sound to Khunthiya then its beating is called "longlai bunai". Longlai bunai means Batha is catch openly by one hand in one side and it is beated in a long distance.

If the count is ended with "Ver" sound to Khunthiya then its beating is called "Athingao Bunai". Athingao
Bunai means Batha is kept on a foot and beated it to a ong distance.

If the count is ended with "Rwo" sound to Khunthiya then its style of beating is by one hand only. The Laothi (Batha Bugra) is catch tightly by a hand but major portion of the Laothi is kept upward and Batha is kept in the downward part of the Laothi and beated it to a long distance.

If the count is ended with "Raas" sound to Khunthiya then its style of beating is also by one hand only. The Batha and the Laothi (Batha bugra) are catches tightly together by a hand and beated the Batha leaving on upward. This is called as Homzab Bunai.

If the count is ended with "Paas" sound to Khunthiya then its style of beating is also by single hand only. The Laothi (Batha Bugra) is catch by a hand but the major portion of the Laothi is kept in downward only a little portion is kept upward and Batha is kept on this portion and threw it up to sky and beated by the lower portion of the Laothi.

In every beating the fielders are tried to catches the Batha. If they failed to catches the Batha then they through to Khunthiya and tried to touch the Khunthiya. On the other hand in every through the beater also tried to beat again the Batha in a long distance for their safety and more scores.

All the players of a team are beated up to end one by one with same processes. The total score of a team will be depends upon the total "Er, Ver, Rwo, Raas, Paas" count by them in whole the game or their winnings.

After the end of $1^{\text {st }}$ winnings or first team the next team will cum to beat or start their winnings with same processes. At the end of the game total scores made by each team are counted. And, which team have made more scores, that team will win the match. It is also important to know that how many more scores was made by the wining team the opposition team will be defected that number of Game, which is known as "Gang Khazanai".

It is also observed that the counting song of "Batha Gelenai" for score is differing by their geographical areas within Baksa District. Some parts are counts with song "Er, Ver, Rwo, Raas, Paas" and some parts of the District are count with song "Eka, Bira, Tira, Swora, Pansal, Jwl, $B w l$ Bota". But whole the scoring system and methods of play are same within the District.

\section{Result of the Analysis}

From the above analysis it is clearly observed that really Batha Gelenai is one of the most important Traditional Games and Recreation of the Bodos of Baksa District. No social fait has been found for this game. It is played for enjoyment only. Normally this Game is a kind of Group Game played by young boys only. But sometime adult male also played this Game for their enjoyment. Dry and open paddy field is the best playground for this Game and still today it is played at dry season only in Baksa District. 
It is also clearly observed that really it is a kind of very interesting and dangerous Game of the Bodos. Lack of practice sometimes some players are to be injured during this Game. It is also observed that in today use of some playing materials like use of Begors during the play has changed. Today Marbles are also used in place of Begors. By observing whole the process and methods of Batha Gelenai it can be said that it is like a present Cricket Game. So it is needed for a deep study and updated some playing method and process for the modernization of this Game. It is very important to preserve it for future.

\section{Expected Out-put and Conclusion}

It is expected that the proposed study on Traditional games and Recreations of the Bodos will open a new vistas to the other ethnic culture of North-East region in particular and all other Tribal society of the Sino-Tibetan Family. The present study will pave a way to develop a corelation between the physical and mental development of the Bodo society. This world certainly enhances the scientific way. Through this research traditional games and recreation of the Bodos will be enhanced in scientific platform.
It is expected that the propose study of Bodo culture will advocate the unique features of Bodo culture to the world community and opening a new horizon to the cultural researches.

It is also expected that after the completion of these research Traditional games and recreations of the Bodo will be spread to the other community of this challenging world. To developed the Traditional Games and Recreations of the Bodo society is the main aims and objectives of the selecting this research topic.

\section{References}

[1] Dorson, R.M. (ed.) (1972), "Folklore and Folk life; An Introduction", University of Chicago press, p-173

[2] Sarma, S.N. (1989), "A Socio-Economic and Cultural History of Medieval Assam", Saumar printers, Guwahati, p-319

[3] Kothari, C.R. (1985), "Research Methodology", New Age International ( $p$ ) Limited, Publishers

[4] Chatterji, S.K. (1991), "The place of Assam in the History and Civilization of India", $3^{\text {rd }}$ Print, Gauhati University, Assam

[5] Narzaree, B. (2003),"Brahmaputra Upatyakar Boro Sakalar Samajik Lokachar: Eti Vislesanatmak Adhyayana", Unpublished Thesis, Gauhati University, Assam 